\title{
Autism Awareness Scale for Security Officers Working in Hospitals: A Study of Validity and Reliability
}

Melda Karavus ${ }^{1}$ (D), Seyhan Hidiroglu ${ }^{1}$ (D), Alican Sarisaltik ${ }^{1}$ (D), Can llgin ${ }^{1}$ (D), Gulsum Hatice Yuksel ${ }^{2}$ (D), Abdullah Omer Seker ${ }^{2}$ (D), Pinar Kumru ${ }^{3}$ (D), Dilsad Save ${ }^{1}$ (D), Nimet Emel Luleci ${ }^{1}$ (D)

${ }^{1}$ Marmara University, School of Medicine, Department of Public Health, Istanbul, Turkey.

${ }^{2}$ Marmara University, Health Sciences Institute, Public Health PhD Program, Istanbul, Turkey.

${ }^{3}$ Turkish Ministry of Health, Istanbul Provincial Health Directorate, Zeynep Kamil Women and Children Diseases Training and Research Hospital, Istanbul, Turkey.

Correspondence Author: Alican Sarisaltik

E-mail: dr.alicansarisaltik@gmail.com

Received: $06.08 .2020 \quad$ Accepted: 26.10 .2020

\begin{abstract}
Objective: The purpose of this study was to evaluate the knowledge and awareness toward autism among security officers working in hospitals and to explore the validity and reliability of the Autism Awareness Scale for Security Officers (AASSO) developed by the researchers.

Methods: This methodological study was conducted at two Government Training and Research Hospitals in Istanbul, Turkey. A total of 135 security officers were included in the study and the data were obtained between February and April 2019. The AASSO is a 4-point Likert type scale and consists of 20 items. The factor structure of the scale was extracted by performing exploratory factor analysis.

Results: Most of the participants were male ( $n=79 ; 58.5 \%$ ) and high school graduates ( $n=86 ; 67.7 \%)$. Participants considered autism mostly as "a kind of mental retardation" ( $n=69 ; 51.9 \%$ ), followed by "social interaction problem" ( $n=24 ; 18.0 \%)$. The AASSO reduces autism awareness into 3 factors ('Coming across', 'Communication' and 'Interaction with the environment'), with eigenvalues ranging from 9.417 to 1.201 and explained $65.45 \%$ of all variance. Cronbach's alpha values for the AASSO was 0.936 and ranged from 0.921 to 0.809 for the subscales.

Conclusion: According to these results AASSO is a valid and reliable scale. The consequence of further studies especially conducted on nonhealthcare professionals of hospitals should be establishing autism-friendly hospitals.

Keywords: Autism, awareness, reliability, scale, validity.
\end{abstract}

\section{INTRODUCTION}

Autism spectrum disorder (ASD) is a neurodevelopmental condition that has many forms and affects people in varying degrees. Characteristic features include; lack of social interaction and communication, and limited and repetitive behavior patterns in terms of interests and activities $(1,2)$. Although the frequency is unclear, studies have shown that the prevalence of ASD is increasing and has recently found as 1 in 54 (18.5 per 1,000) among children aged 8 years (3). The exact causes of autism are unknown; however, it was concluded that autism is resulting from combination of genetic and environmental risk factors (4).

Autism awareness is important for many reasons both in society and in various professions. Raising awareness about autism will allow recognition of the differences of individuals with autism and ensure the right approach in social areas. Autism is commonly associated with poor emotional control, anxiety and impulsivity $(5,6)$. The challenging behaviors of individuals with autism including aggression to others are frequently observed and not socially acceptable $(7,8)$. Because people with autism cannot hide their minds, can be overly impulsive and cannot internalize social rules they can often remain in a disorder or debate. In addition, a stressful and controversial environment, such as a hospital, can cause anger and crisis in people with autism. In such cases in the hospital, security officers are the first responders. The officers should recognize autism and the moment of crisis and be able to distinguish it from other situations such as the substance and alcohol addiction crisis. They should be able to manage this moment of crisis by calming the individual with autism and his/her family. Furthermore, in most hospitals in Turkey, security officers are the first personnel individuals having autism meet at the hospital environment. The security officer's attitude and behaving as a facilitator for them reaching the hospital's health services may be very important.

Although there are previous studies with community, teachers and healthcare professionals about knowledge and awareness of autism, this subject has not been adequately researched on the security officers (9-12). The aim of this research was to evaluate the knowledge and awareness 
toward autism among security officers working in hospitals and to explore the validity and reliability of the Autism Awareness Scale for Security Officers (AASSO) developed by the researchers.

\section{METHODS}

\subsection{Study Design and Participants}

The study was designed as a methodological research. The population of the study consisted of 155 security officers working in two Government Training and Research Hospitals in Anatolian side of Istanbul. All security officers who was volunteer to participate in the research were considered eligible for the study. A total of 135 security officers working in these hospitals were participate (response rate=87.1\%).

\subsection{Data Collection and Instruments}

The data of the study were collected between February and April 2019. An anonymous self-completed survey consisted of 32 questions was used for data collection. Before collected the data, a pilot study was done to test the survey with a smaller sample for determine whether questions are interpreting as intended.

The initial question of the survey was a case question describing a typical situation an individual having autism might come across while waiting at the hospital and the security officer's attitude while handling the situation. The English version of initial case question is presented at the appendix. In addition, five questions about sociodemographic characteristics of the participants, two questions evaluating the general level of knowledge on autism and four questions inquiring any experience of the participants with an individual having autism were included in the first part of the survey.

The AASSO was developed by researchers to measure autism awareness level of security officers working in hospitals. It is a 4-point Likert scale (1=strongly disagree, 2=disagree, $3=$ agree, $4=$ strongly agree) and consists of 20 items. The total scores of respondents vary from 20 to 80 , and higher scores indicate better level of awareness.

\subsection{Ethical Statement}

Ethical approval for the study was obtained from the Ethics Committee of Zeynep Kamil Women and Children Diseases Training and Research Hospital (19/12/2018 - 159) and research permissions were taken from the Health Promotion Unit of Istanbul Provincial Health Directorate. Our study was conducted according to the Declaration of Helsinki and written informed consent was obtained from all participants.

\subsection{Statistical Analysis}

The statistical analysis was carried out by using IBM SPSS Statistics for Windows, version 23 (IBM Corp., Armonk, N.Y.,
USA). Sample characteristics are presented as frequency tables and mean \pm standard deviation values. Exploratory factor analysis was performed on the scale items to determine the construct validity of the AASSO. Factors were extracted by using eigenvalue-one criterion. The Kaiser-Meyer-Olkin measure of sampling adequacy and the Bartlett's Test of Sphericity were calculated to verify the suitability of applying the factor analysis to the data. The internal consistency was measured using Cronbach's alpha, item-total correlations, and the mean inter-item correlation. Correlations between the AASSO and the subscales were examined using the Spearman's rank correlation coefficient.

\section{RESULTS}

Sociodemographic characteristics of the participants are presented in Table 1 . Most of the participants were men $(n=79 ; 58.5 \%)$ and high school graduates $(n=86 ; 67.7 \%)$. The mean age of participants was $34.43 \pm 6.76$ years. A high fraction of participants stated that they have ever heard of the word of autism $(n=128 ; 95.5 \%)$ and they saw an individual with autism ( $n=93 ; 68.9 \%)$. In addition, twenty three participants $(17.0 \%)$ stated that they have a relative with autism.

Table 1. Characteristics of the Participants

\begin{tabular}{|c|c|c|c|}
\hline & n & $\%$ \\
\hline \multirow[t]{2}{*}{ Gender } & Female & 56 & 41.5 \\
\hline & Male & 79 & 58.5 \\
\hline \multicolumn{2}{|l|}{ Age (years) } & \multicolumn{2}{|c|}{$34.43 \pm 6.76^{*}$} \\
\hline \multirow[t]{4}{*}{ Graduate } & $\begin{array}{l}\text { Elementary } \\
\text { school }\end{array}$ & 2 & 1.6 \\
\hline & Junior high school & 23 & 18.1 \\
\hline & High school & 86 & 67.7 \\
\hline & University & 16 & 12.6 \\
\hline \multicolumn{2}{|c|}{ Working experience as a security officer (years) } & \multicolumn{2}{|c|}{$6.12 \pm 3.90^{*}$} \\
\hline \multicolumn{2}{|c|}{ Working experience in current hospital (years) } & \multicolumn{2}{|c|}{$4.30 \pm 2.97^{*}$} \\
\hline \multirow[t]{3}{*}{ Ever heard of autism } & Yes & 128 & 95.5 \\
\hline & No & 4 & 3.0 \\
\hline & Do not know & 2 & 1.5 \\
\hline \multirow[t]{3}{*}{ Family member with autism } & Yes & 23 & 17.0 \\
\hline & No & 111 & 82.2 \\
\hline & Do not know & 1 & 0.7 \\
\hline \multirow{3}{*}{$\begin{array}{l}\text { Anyone with autism in close } \\
\text { social circle }\end{array}$} & Yes & 34 & 25.2 \\
\hline & No & 94 & 69.6 \\
\hline & Do not know & 7 & 5.2 \\
\hline \multirow{3}{*}{$\begin{array}{l}\text { Ever saw an individual with } \\
\text { autism }\end{array}$} & Yes & 93 & 68.9 \\
\hline & No & 38 & 28.1 \\
\hline & Do not know & 4 & 3.0 \\
\hline
\end{tabular}

\footnotetext{
* Mean \pm standard deviation
}

The most common answer of the participants for describing the character in the initial case question was "autism" ( $n=66$; $50.0 \%)$, which has been followed by "mental retardation" $(n=48$; \%36.6). An important fraction of the participants answered the onset symptoms of autism show up "between 
the ages of $0-1$ " ( $n=64 ; 47.8 \%)$. Most participants considered autism as "a kind of mental retardation" ( $n=69 ; 51.9 \%)$ and "social interaction problem" ( $n=24 ; 18.1 \%)$ (Table 2).

Table 2. Participants' Answers to Knowledge Questions About Autism

\begin{tabular}{|c|c|c|c|}
\hline \multirow{7}{*}{ Case question } & & $n$ & $\%$ \\
\hline & Autism & 66 & 50.0 \\
\hline & Mental retardation & 48 & 36.4 \\
\hline & Do not know & 8 & 6.0 \\
\hline & Alcohol or substance abuse & 5 & 3.8 \\
\hline & Conversion & 3 & 2.3 \\
\hline & Other & 2 & 1.5 \\
\hline \multirow[t]{5}{*}{ Definition of autism } & A kind of mental retardation & 69 & 51.9 \\
\hline & Social interaction problem & 24 & 18.0 \\
\hline & Strange repetitive behaviors & 21 & 15.8 \\
\hline & Speaking problem & 7 & 5.3 \\
\hline & Other & 12 & 9.0 \\
\hline \multirow{4}{*}{$\begin{array}{l}\text { Onset symptoms of } \\
\text { autism show up }\end{array}$} & Between the ages of $0-1$ & 64 & 47.8 \\
\hline & Between the ages of 2-5 & 61 & 45.5 \\
\hline & Between the ages of 6-12 & 7 & 5.2 \\
\hline & Between the ages of $12-18$ & 2 & 1.5 \\
\hline
\end{tabular}

The Kaiser-Meyer-Olkim (KMO) measure of sampling adequacy was 0.864 and the Bartlett's Test of Sphericity $(\chi 2=1753.83, \quad p<0.001)$ was statistically significant, supporting the factorability of the data. According to the principal factor analysis with varimax rotation were extracted 3 factors with eigenvalues greater than 1.0 ranging from 9.417 to 1.201 . These 3 factors explained $65.44 \%$ of all variance. Factor 1 (Coming across) explained that $47.09 \%$ of the total variance and contained 8 items regarding the events and observations experienced by the security officers when they come across with an individual having autism. Factor 2 (Communication) contributed to the explanation of $12.36 \%$ of the total variance and had 7 items about the communication problems, which may be experience between the security officers and an individual with autism. Finally, factor 3 (Interaction with the environment) explained $6.00 \%$ of the total variance, contained 5 items regarding the interaction of an individual having autism with his/her environment (Table 3 ).

Table 3. Factor Structure of the Autism Awareness Scale for Security Officers (AASSO)

\begin{tabular}{|c|c|c|c|c|c|}
\hline & & \multicolumn{3}{|c|}{ Factor* } & \multirow{2}{*}{$\begin{array}{l}\text { Item-Total } \\
\text { Correlation }\end{array}$} \\
\hline & & 1 & 2 & 3 & \\
\hline & \multicolumn{5}{|l|}{ Factor 1: Coming across with an individual having autism } \\
\hline 1. & They may say stereotypic words/sentences again and again, as they talk themselves. & 0.825 & 0.217 & 0.091 & 0.701 \\
\hline 2. & A child with autism may swing his/her hands like a bird clapping its wings. & .796 & .275 & .010 & .685 \\
\hline 4. & They may scream and act rapidly. & .771 & .237 & .221 & .726 \\
\hline 7. & They may play with a toy/thing continuously by shaking or turning. & .760 & .275 & .257 & .759 \\
\hline 5. & A child with autism may shake himself/herself for a long time. & .746 & .308 & .157 & .731 \\
\hline 6. & A child with autism may stare blank. & .728 & .379 & .193 & .777 \\
\hline 3. & A child with autism may turn around himself/herself and on his/her toe. & .695 & .341 & -.018 & .645 \\
\hline \multirow[t]{2}{*}{8.} & They may be bored during waiting in line. & .599 & .429 & .295 & .749 \\
\hline & \multicolumn{5}{|l|}{ Factor 2: Communication with an individual having autism } \\
\hline 11. & They will not response when they are called by their name when they are with other people in public. & .190 & .824 & -.020 & .565 \\
\hline 10. & They may have trouble by understanding what people say to them. & .292 & .769 & .108 & .662 \\
\hline 9. & They may have trouble by expressing themselves. & .347 & .738 & .113 & .683 \\
\hline 12. & They may have trouble when they communicate with people with signs and body language. & .432 & .612 & .241 & .723 \\
\hline 13. & They have trouble by establishing eye contact with people. & .458 & .600 & .256 & .743 \\
\hline 14. & They may response to questions by repeating them like as parrot. & .444 & .596 & .174 & .699 \\
\hline \multirow[t]{2}{*}{15.} & Their voice may be thin and monotonic like a robot. & .497 & .587 & .121 & .712 \\
\hline & \multicolumn{5}{|l|}{ Factor 3: Interaction with the environment of an individual having autism } \\
\hline 18. & They do not like to be touched during tantrums. & .033 & -.040 & .889 & .305 \\
\hline 17. & $\begin{array}{l}\text { They may overreact to cry of baby, ambulance sounds, or hums/murmurs and they may experience } \\
\text { emotional breakdowns/tantrums. }\end{array}$ & .028 & .013 & .839 & .315 \\
\hline 19. & If they are taken to a quiet room during their tantrum, their rage reduces rapidly. & .242 & .112 & .724 & .473 \\
\hline 16. & They may be uncomfortable in loud places and they do not want to hear voices. & .134 & .192 & .678 & .432 \\
\hline 20. & $\begin{array}{l}\text { A child with autism may do wrong things to reach a specifically desired object without considering the } \\
\text { criminal element of his/her behavior. }\end{array}$ & .199 & .329 & .571 & .512 \\
\hline \multicolumn{6}{|c|}{$\begin{array}{l}\text { *Principal component analysis with orthogonal varimax rotation. Bartlett's Test of Sphericity was } \chi 2=1753.83, p<0.001 \text { and Kaiser-Meyer-Olkin was } 0.864 ; \\
\text { Cronbach's alpha }=0.936 \text { ( } 0.890 \text { for Factor } 1 ; 0.921 \text { for Factor } 2 ; 0.809 \text { for Factor 3); Total variance explained } 65.45 \%(47.09 \% \text { Factor } 1 ; 12.36 \% \text { Factor } 2 ; \\
6.00 \% \text { Factor 3); Eigenvalues for the three factors were } 9.417,2.471 \text {, and 1.201, respectively. }\end{array}$} \\
\hline
\end{tabular}


The item-total correlations were ranging between 0.305 and 0.777 and the mean inter-item correlation was 0.423 of the 20-item AASSO. The Cronbach's alpha value for the scale was 0.936 and ranging from 0.921 to 0.809 for the subscales (Table 3 ). The AASSO subscales were highly or moderately correlated with the total scale score (Coming across: $r=0.924$, Communication: $r=0.928$, Interaction with the environment: $r=0.478$ ) and correlated with each other (Coming across and Communication: $r=0.795$, Coming across and Interaction with the environment: $r=0.330$, Communication and Interaction with the environment: $r=0.317$ ) (Table 4).

Table 4. Correlations between the Autism Awareness Scale for Security Officers (AASSO) and the subscales

\begin{tabular}{|l|c|c|c|c|}
\hline & AASSO & $\begin{array}{c}\text { Coming } \\
\text { across }\end{array}$ & Communication & $\begin{array}{c}\text { Interaction } \\
\text { with the } \\
\text { environment }\end{array}$ \\
\hline AASSO & - & $0.924^{* *}$ & $0.928^{* *}$ & $0.478^{* *}$ \\
\hline Coming across & $0.924^{* *}$ & - & $0.795^{* *}$ & $0.330^{* *}$ \\
\hline Communication & $0.928^{* *}$ & $0.795^{* *}$ & - & $0.317^{* *}$ \\
\hline $\begin{array}{l}\text { Interaction with } \\
\text { the environment }\end{array}$ & $0.478^{* *}$ & $0.330^{* *}$ & $0.317^{* *}$ & - \\
\hline
\end{tabular}

\section{DISCUSSION}

In this methodological study, most participants having heard the word autism before and having encountered with an individual having autism before. Although the majority of the respondents correctly answered as 'autism' to the initial case question, there was a similar frequency of those who stated, 'mental retardation'. In addition, most participants stated, 'a kind of mental retardation' as the definition of autism instead of 'social interaction problem'. Autism is characterized by social skills deficits, stereotypical behaviors and difficulties in communication and does not have to be with mental retardation. However, a recent study stated that $33.4 \%$ of children with ASD were classified in the range of intellectual disability (intelligence quotient $[I Q] \leq 70)$ and $24.1 \%$ were in the borderline range $(I Q=71-85)(3)$. The level of knowledge about the relationship between autism and mental retardation has been questioned in different ways in the literature. In a community awareness study, only $19 \%$ of respondents agreed to the phrase 'autism is similar to mental retardation', whereas, approximately half of respondents thought 'autism is a learning and mental disorder' in another study on primary school teachers $(9,10)$.

In our study, most participants stated that onset symptoms of autism show up "between the ages of 0-1" which has been followed by "between the ages of 2-5" (47.8\% and 45.5\%; respectively). Previous studies suggest that symptoms and signs including lack of eye contact, no social smiling or failure to respond to name may predict autism between 6-12 months; however, identification of autism in the first year of life may not be possible in the majority of affected children $(13,14)$. The American Academy of Pediatrics recommended to screening at 18 and 24 months of age for ASD (15). Early diagnosis is critical because early interventions can provide the best opportunity to promote healthy development and provide lifelong benefits $(16,17)$.

The AASSO developed by us and used in our study was found to be a reliable scale in terms of Cronbach's alpha value (0.936) (18). According to the factor analysis of the data, the model could explain $65.45 \%$ of the variance which indicated within acceptable range (19). Factor 1 emphasizes the events which can be experienced by the security officers when they come across with an individual having autism. In a previous narrative, the importance of nonverbal communication in first contact and the desire of the individuals to be recognized, were emphasized (20). If the security officers establish communication with the individual having autism, they may experience the communication challenges defined by the items loaded to factor 2 . The communication problems which are experienced by the individuals with autism are well described and may affect social functioning $(21,22)$. The security officers may experience the reactions of the individual with autism defined by the items loaded to factor 3. The reactions of children having autism may range from tantrums to avoidance, thus the management of these reactions in children with autism is challenging (23). Therefore, this model may separate the items according the components of the social interaction between the security officers and individual having autism. All the correlations between the AASSO and subscales were found to be high or moderate. However, the correlations of factor 3 with factor 1 and factor 2 were low ( 0.330 and 0.317 ; respectively). This may be the result of while the items loaded on factor 1 and factor 2 are related to interpersonal interactions, items loaded to factor 3 are related to recognize interaction between individual having autism and his/her environment. In our study the mean inter-item correlation was 0.423 , which falls in the range of $0.15-0.50$ and considered as an acceptable level of consistency (24). Furthermore, itemtotal correlations of the items were between 0.305 to 0.777 , exceeding the benchmark value of 0.30 (25).

The most important novelty of our study is the development of internally valid scale which can be separated into 3 factors, which explain $65.45 \%$ of total variance and are loaded with the items explaining various facets of the social interaction between the security officers and individuals with autism. This study is a guidance on issues to be considered in the training of security officers in terms of autism awareness.

The participants' marking autism among other choices as the answers of the initial case question could be interpreted as a bias, and this could not be controlled. This can be a limitation of our study. Conversely, using multiple choice answers for case questions can occasionally be considered being superior to open ended question (26). Thus, in our study we think we used the optimal methods like multiple-choice questions and Likert type of questions to measure the knowledge and awareness of participants about autism. Furthermore, we avoided using open-ended questions thinking the shortage of time of the participants to complete the survey. 


\section{CONCLUSION}

Our results show that the AASSO is a valid and reliable measurement instrument. It inquires autism awareness in this occupational group by reducing it to three main dimensions (Coming across, Communication and Interaction with the environment) and gives guidance for detection and improvement of weak points in social interaction of security officers with individuals having autism. Not only security officers at hospitals but also other non-healthcare professionals working at hospitals should be inquired for their autism awareness by conducting further researches. The optimum consequence of these further studies should be establishing autism-friendly hospitals.

\section{Acknowledgments}

We owe special thanks to Dr. Ayşe Eren, Dr. Banu Çelik, Dr. Beyza Kabayuka, Dr. Erşat Ersagun Ekici, Dr. Özge Savrin and Dr. Neşe Keskin who have participated in the pilot study.

\section{REFERENCES}

[1] Lai MC, Lombardo MV, Baron-Cohen S. Autism. The Lancet 2014; 383:896-910.

[2] American Psychiatric Association. Diagnostic and statistical manual of mental disorders. 5th ed. Arlington, VA: American Psychiatric Association; 2013.

[3] Maenner MJ, Shaw KA, Baio J, Washington A, Patrick M, DiRienzo M, Christensen DL, Wiggins L, Pettygrove $S$, Andrews JG, Lopez M, Hudson A, Baroud T, Schwenk Y, White T, Robinson Rosenberg C, Lee LC, Harrington R, Huston M, Hewitt A, Esler A, Hall-Lande J, Poynter JN, Hallas-Muchow L, Constantino JN, Fitzgerald RT, Zahorodny W, Shenouda J, Daniels JL, Warren Z, Vehorn A, Salinas A, Durkin MS, Dietz PM. Prevalence of Autism Spectrum Disorder Among Children Aged 8 Years - Autism and Developmental Disabilities Monitoring Network, 11 Sites, United States, 2016. MMWR Surveill Summ 2020; 69:1-12.

[4] Chaste P, Leboyer M. Autism risk factors: genes, environment, and gene-environment interactions. Dialogues Clin Neurosci 2012; 14:281-292.

[5] Lecavalier L. Behavioral and emotional problems in young people with pervasive developmental disorders: relative prevalence, effects of subject characteristics, and empirical classification. J Autism Dev Disord 2006; 36:1101-1114.

[6] Mazefsky CA, Herrington J, Siegel M, Scarpa A, Maddox BB, Scahill $L$, White SW. The role of emotion regulation in autism spectrum disorder. J Am Acad Child Adolesc Psychiatry 2013; 52:679-688.

[7] Goodwin MS, Mazefsky CA, loannidis S, Erdogmus D, Siegel M. Predicting aggression to others in youth with autism using a wearable biosensor. Autism Res 2019; 12:1286-1296.

[8] Kanne SM, Mazurek MO. Aggression in children and adolescents with ASD: Prevalence and risk factors. J Autism Dev Disord 2011; 41:926-937.
[9] Arif MM, Niazy A, Hassan B, Ahmed F. Awareness of autism in primary school teachers. Autism Res Treat 2013; 2013:1-5.

[10] Alsehemi MA, Abousaadah MM, Sairafi RA, Jan MM. Public awareness of autism spectrum disorder. Neurosciences (Riyadh) 2017; 22:213-215.

[11] Chansa-Kabali T, Nyoni J, Mwanza H. Awareness and knowledge associated with autism spectrum disorders among university students in Zambia. J Autism Dev Disord 2019; 49:3571-81.

[12] Heidgerken AD, Geffken G, Modi A, Frakey L. A survey of autism knowledge in a health care setting. J Autism Dev Disord 2005; 35:323-30.

[13] Ozonoff S, losif AM, Baguio F, Cook IC, Hill MM, Hutman T, Rogers SJ, Rozga A, Sangha S, Sigman M, Steinfeld MB, Young GS. A prospective study of the emergence of early behavioral signs of autism. J Am Acad Child Adolesc Psychiatry 2010; 49:256-66.e1-2.

[14] Zwaigenbaum L, Bryson S, Rogers T, Roberts W, Brian J, Szatmari P. Behavioral manifestations of autism in the first year of life. Int J Dev Neurosci 2005; 23:143-52.

[15] Johnson CP, Myers SM. Identification and evaluation of children with autism spectrum disorders. Pediatrics 2007; 120:1183-215.

[16] Elder JH, Kreider CM, Brasher SN, Ansell M. Clinical impact of early diagnosis of autism on the prognosis and parent-child relationships. Psychol Res Behav Manag 2017; 10:283-92.

[17] Manohar H, Kandasamy P, Chandrasekaran V, Rajkumar RP. Early diagnosis and intervention for autism spectrum disorder: Need for pediatrician-child psychiatrist liaison. Indian J Psychol Med 2019; 41:87-90.

[18] Barron D, Morgan KD, Towell T, Jaafar JL, Swami V. Psychometric properties of the Malay Schizotypal Personality Questionnaire: Measurement invariance and latent mean comparisons in Malaysian adults. Asia Pac Psychiatry 2018; 10:e12293.

[19] Hair JF, Black WC, Babin BJ, Anderson RE. Multivariate Data Analysis: Pearson New International Edition. 7th ed. Harlow, United Kingdom: Pearson Education Limited; 2014.

[20] Baker SM. Learning about autism. Glob Adv Health Med 2013; 2:38-46.

[21] Garfin DG, Lord C. Communication as a Social Problem in Autism. In: Schopler E, Mesibov GB, editors. Social Behavior in Autism. Boston, MA: Springer; 1986. pp.131-155.

[22] Stankovic M, Lakic A, Ilic N. Autism and autistic spectrum disorders in the context of new DSM-V classification, and clinical and epidemiological data. Srp Arh Celok Lek 2012; 140:236-243.

[23] Tureck K, Matson JL, Cervantes P, Konst MJ. An examination of the relationship between autism spectrum disorder, intellectual functioning, and comorbid symptoms in children. Res Dev Disabil 2014; 35:1766-72.

[24] Clark LA, Watson D. Constructing validity: Basic issues in objective scale development. Psychol Assess 1995; 7:309-19.

[25] Cristobal E, Flavián C, Guinalíu M. Perceived e-service quality (PeSQ): Measurement validation and effects on consumer satisfaction and web site loyalty. Manag Serv Qual 2007; 17:317-40.

[26] Medina MS. Relationship between case question prompt format and the quality of responses. Am J Pharm Educ 2010; 74:29.

How to cite this article: Karavus M, Hidiroglu S, Sarisaltik A, Ilgin C, Yuksel GH, Seker AO, Kumru P, Save D, Luleci NE. Autism Awareness Scale for Security Officers Working in Hospitals: A Study of Validity and Reliability. Clin Exp Health Sci $2021 ; 11: 14-19$. DOI: $10.33808 /$ clinexphealthsci. 777110 


\section{APPENDIX}

Case Question: A 14-year-old boy was waiting for examination order at emergency with his family since his brother had a fever. The child had little interest in his environment and repeated himself some words. He had a pensive state. During the waiting, he noticed a man trying to get ahead of his mother on the line and started pulling and kicking his arm. In this case, the man started shouting to call security. The child became more irritable with the noise and started to spin around himself. The security officer tried to calm other individuals and prevent the confusion of the environment instead of stopping the child by using force. After the place became calm the security officer talked with the family members in line and directed them to the required department. The child calmed down in a quiet place.

What do you think could be the diagnosis of the 14-year-old boy mentioned above?

( ) Substance or Alcohol addiction

( ) Mental Retardation

() Autism

( ) Epilepsy Seizure

( ) Conversion Disorder

( ) I do not know.

( ) Other (please specify ...) 